\title{
2006-67: HOMEWORK AS AN OUTCOME ASSESSMENT: RELATIONSHIPS BETWEEN HOMEWORK AND TEST PERFORMANCE
}

\section{Abel Fernandez, University of the Pacific}

Abel A. Fernandez is Associate Professor of Civil Engineering at the University of the Pacific. He received degrees from Rensselaer Polytechnic (B.S., Electric Power Engineering; M.E., Electric Power Engineering; MBA) and the University of Central Florida (Ph.D., Industrial Engineering). Prior to joining academia, he held positions of system engineer and Director of Product Marketing with the Harris Corporation, Florida. In 2000, he joined the University of the Pacific as Director of the Engineering Management Program.

\section{Camilla Saviz, University of the Pacific}

Camilla M. Saviz, Ph.D., P.E., holds B.S. and M.S. degrees in Mechanical Engineering from Clarkson University, an MBA from the New York Institute of Technology, and a Ph.D. degree in Civil and Environmental Engineering from U.C. Davis. She is currently an associate professor in the Department of Civil Engineering at the University of the Pacific. Dr. Saviz' research interests include measurement and modeling of hydrodynamics, water quality, and sediment transport in surface water systems. She has also served as co-principal investigator on several studies to develop and implement strategies to enhance the quality of engineering education.

\section{Jeff Burmeister, University of the Pacific}

Jeffrey S. Burmeister earned his B.S. in mechanical engineering from the University of Delaware in 1988 and his Ph.D. in biomedical engineering from Duke University in 1995. He has been a faculty member of the Department of Mechanical Engineering at the University of the Pacific since 2002 and presently is Assistant Professor and Director of the Bioengineering Program. 


\title{
Homework as an Outcome Assessment: Relationships Between Homework and Test Performance
}

\begin{abstract}
Homework imposes a significant load on undergraduate engineering students and faculty, and typically represents 10 to 30 percent of a student's final course grade. One of the fundamental purposes of homework is to help students master the course material, mastery ultimately assessed through quizzes, tests and a final examination. To understand whether homework grades are a significant factor in determining student performance on tests, a study was conducted to examine the correlation between individual student scores on homework, quizzes, tests and final examination. Data from four courses taught by three different instructors showed very weak correlation between homework and quiz, test or final examination scores, respectively; much stronger correlations were found between quiz, tests and final examinations. Multiple linear regressions were developed for three courses, with quiz and test scores found to be the only statistically significant predictors of final examination performance (homework was found not to be a statistically significant predictor). Study results indicate that graded homework may potentially not be an effective means of enhancing student performance on tests. Areas of potential future research extensions are discussed.
\end{abstract}

\section{Introduction}

Engineering Mechanics I (Statics) is typically among the first core engineering courses taken by students, and thus represents a critical educational career juncture. Yet, over the past year approximately 50\% of students taking Statics at the University of the Pacific got a course grade of $\mathrm{D}+$ or below, despite getting very high homework assignment grades. This seeming contradiction prompted a study to examine, at an individual student level, the relationships between homework assignment grades and traditional course performance outcome measures; i.e., quizzes, tests and final examination.

Substantial homework is dogmatically accepted as an indispensable component of engineering courses. Faculty reflect on their own education and proudly maintain a traditionally heavy homework load as a rite of passage, while students resignedly accept the heavy workload as part of the cost of entering into the engineering profession. The nature of engineering, as with other hard sciences, is such that conceptual and practical understanding comes from applying principles and techniques to solve problems ${ }^{1}$. To provide incentive for students to practice problem solving, assigned homework is typically collected, graded and returned to students. Contemporary pedagogical thinking, however, focuses not on teaching "to tradition" but rather on achieving student learning outcomes: a process should be established that defines desired learning outcomes, 
assesses attainment of these outcomes and molds teaching techniques to maximize the achievement of defined learning outcomes ${ }^{2}$.

One of the fundamental purposes of homework is to help students master the course material, a mastery ultimately assessed through quizzes, tests and a final examination. A student's grade in a course is ideally a measure of proficiency in the subject matter, and an indicator for attainment of defined learning outcomes. The final grade is typically a composite of grades given during the semester for homework, quizzes, tests, laboratory assignments, projects and a final examination. Although the weight given to each component varies by course and instructor, engineering homework at the University of the Pacific usually accounts for 10 to 30 percent of the course grade. Faculty assign a relatively high weight to homework to provide meaningful incentive for students to complete assignments. A lower weight may lead to students considering trade-offs between spending time on either homework or other responsibilities. Considering the heavy student workload in engineering, a lower weight assigned to homework may ultimately marginalize its role within the course and the learning process.

An underlying assumption on the part of faculty is that homework grades reflect personal understanding and effort, and thus are valid measures of individual student outcomes. Homework unquestionably reflects the nature of engineering practice, wherein problems are solved in an open setting in marked contrast to time-constrained and "closed book" test conditions. However, the combination of an open setting and the pressure to perform well on homework may lead students to deleterious study-group work habits with excessive reliance on support from peers. Quizzes, tests and final examinations, in contrast, are administered in a controlled setting wherein each student is solely responsible for their own work. Though tests are perhaps imprecise assessment methods of student learning outcomes, they are undoubtedly ubiquitous in engineering education and accepted as one of the principal means of assessing student learning outcomes in a specific course ${ }^{3}$.

Grading homework imposes a heavy resource load not only on the student but also on the institution. Faculty (and/or teaching assistants) have to spend substantial time collecting and evaluating assignments, recording grades, returning to students, posting on-line and handling other details associated with graded assignments. Additional time is often necessary to deal with the unavoidable grading errors, excused late homework and other minutia that inevitably arise during the semester. Grading homework assignments for a moderately sized class (e.g., between 25 to 35 students) can take a significant proportion of the instructor's time for the course. This time could perhaps be redirected to more effective means of helping students achieve course learning objectives.

The objective of the study presented in this paper was to examine the relationships between individual student performance on graded homework and quizzes, tests and final examinations (hereinafter collectively referred to as tests). The hypothesis is that graded homework is not a significant factor in determining a student's performance on tests. If both graded homework and tests are valid measures of individual student learning then it would be expected that the grades should exhibit high correlation. This paper first 
reviews the literature addressing the role of graded homework within engineering education, followed by a description of the courses examined by this study and the methods used in the analysis. The results and significance of the findings are then presented. Lastly, this paper concludes with a discussion of other benefits derived from homework and potential areas of potential future research.

\section{Literature Review}

Most research on the effectiveness of homework is reported at the pre-college (i.e., K-12) level and focuses on the need for student practice time as a means of reaching satisfactory proficiency levels. The prevailing research at the pre-college level concludes that homework arouses strong passions pro and con on all parties (students, parents, faculty and administrators); that homework is an important means of providing student practice time; that practice time is key to student learning; and, that evaluating and grading homework are indispensable aspects of the homework process ${ }^{4,5,6}$. Although useful as background information, the profound contextual differences between the K-12 setting and the college level do not allow for a simple migration of these findings to undergraduate engineering programs.

Very little research has been reported specifically addressing the effectiveness of graded homework within undergraduate education in engineering and allied fields. Ironically, undergraduate engineering education traditionally places a heavy emphasis on homework without the concomitant research into its pedagogical effectiveness. An investigation of student habits in undergraduate mathematics courses concluded that regular collection and grading of homework is highly correlated with increased study time in mathematics ${ }^{1}$. The authors concluded that students should be held accountable for their time involvement in courses, and that grading homework is one means of motivating students to meet this obligation. However, their study did not address the relationship between time spent on homework and student performance on tests. Although benefits are derived from solving homework problems, the hypothesis presented in the current study is that grading homework may not lead to improved performance on tests.

Aldosary $^{7}$ reports on the correlation between course grade, homework and student attendance, with the objective of examining the impact of mandatory attendance policies at the College of Environmental Design at the King Fahd University of Petroleum and Minerals. His findings indicate a much stronger correlation between homework and overall course grade, than between student attendance and overall course grade. In that paper, he states that homework and attendance are components of the overall course grade, but neither specifies the weight assigned to each nor addresses the significance and impact upon the study of these interdependencies. Although interesting, these results do not directly bear on the present study.

Trussell and Dietz ${ }^{8}$ conducted an experiment to study the effect of graded homework upon test performance in a mathematics course taken by undergraduate electrical engineering students. Their experimental design consisted of two concurrent sections of the same course taught by the same instructor; in one section homework was graded 
while in the other it was not. The experiment was replicated over two semesters, but provided inconclusive results. In one semester, the section with the graded homework had significantly higher test scores than the section without graded homework. The following semester, test performance in the two sections was not significantly different. The authors report that their findings may indicate that resources used to grade homework "may be redirected without degrading the performance of the students" 5 , page

145. However, they temper this finding with the caution that their findings are inconclusive and point out the need for additional research. Although an important backdrop, Trussell and Dietz ${ }^{8}$ examined the relationship between graded homework and test performance at the group (section) level and not at the individual (student) level. The focus of this paper is to report on the relationship between homework and test performance on a student basis, based on widely varying engineering courses taken at different periods in a student's academic career.

\section{Courses Examined}

Relationships between individual student grades in homework, quizzes, tests and final examinations in four different undergraduate engineering courses taught by three different, full-time faculty at the University of the Pacific were examined for this study. The courses were purposefully chosen to represent a combination of disciplines and levels:

Engineering Mechanics I, Statics (ENGR 20) - a lower division, core engineering course taken by all undergraduate engineering students, typically during the second year of study. Since this is likely the first core engineering course taken, there is a heavy emphasis on homework (one assignment for each class period) and frequent testing of material. Assignments typically consist of three to four problems requiring application of fundamental concepts to well structured problems. Homework problems and test instruments (quizzes, tests and final examination) both assess the same set of skills and knowledge outcomes.

Fluid Mechanics (CIVL 130) - an upper division course required of all civil and mechanical engineering majors, and an elective for other engineering majors. Homework is assigned twice a week, and typically includes three to five problems ranging from application of fundamental concepts to synthesis of material for design-type problems. The skills and knowledge outcomes in the homework are very similar to those assessed during quizzes and tests. Understanding of concepts is also evaluated on tests. Quiz and test problems often require synthesis of material covered on homework and in class.

Water Resources Engineering (CIVL 133) - an upper division course required of all civil engineering majors. The course is a combination of hydraulic and hydrologic analysis and design. Homework is typically assigned once per week, although design problems can span a period of up to two weeks. The skills and knowledge outcomes in the homework are very similar to those assessed during quizzes and tests. Homework design problems may require skills and knowledge 
not assessed by test instruments. Understanding of concepts is also evaluated on tests. Quiz and test problems often require synthesis of material covered on homework and in class.

Engineering Administration (EMGT 170) - an upper division course required of all civil and engineering management majors, and engineering management minors. The course is a combination of engineering economic decision making (engineering economy enhanced with stochastic decision making) and project management fundamentals. Homework is assigned about twice a week during the engineering economics portion of the course (usually four problems applying fundamental concepts), and about once a week during the remainder (one to three problems usually involving more in-depth application of concepts to unstructured problems). Homework problems and test instruments (quizzes, tests and final examination) both assess the same set of skills and knowledge outcomes.

For all four courses, homework grading is rigorous, emphasizing not only correctness of solution but also professional format, completeness of solution approach (e.g., are all solution steps clearly indicated) and adherence to engineering convention (e.g., significant figures, units). For example, the grading rubric used within ENGR 20, Statics, penalizes 15 points for an incorrect solution, 10 points for a correct solution missing the steps used to arrive at the solution, and 5 points for either not showing units or the correct number of significant figures. Key attributes of each course are presented in Table 1. Of particular note is the relatively large number of homework assignments per term for each course: homework clearly represents a significant load on students and faculty.

\begin{tabular}{|l|l|l|l|}
\hline ENGR 20 & CIVL 130 & CIVL 133 & EMGT 170 \\
\hline
\end{tabular}

\begin{tabular}{|l|c|c|c|c|}
\hline Number of sections in study & 4 & 6 & 6 & 8 \\
\hline Total number of students & 108 & 185 & 74 & 168 \\
\hline Average number of students per section & 27 & 31 & 12 & 21 \\
\hline Average number of homework assignments per term & 31 & 22 & 11 & 19 \\
\hline Average number of quizzes per term & 6 & 4 & 3 & $\mathrm{NA}$ \\
\hline Average number of tests per term & 2 & 2 & 2 & 2 \\
\hline Number of final examinations & 1 & 1 & 1 & 1 \\
\hline
\end{tabular}

Table 1. Summary Characteristics of Courses Examined

A data file was constructed for each of the above courses, listing each student's average score on homework, quizzes, tests and final examination. The courses were taught at the University of the Pacific over the past two to five years, spanning the period 1999 to 2005.

\section{Results}

Course data described in the preceding section were analyzed using statistical analysis software. Scatter plots provided a visual indication of the relatively low correlation between the average grade on homework and quizzes, tests or final examination, respectively. Figures 1 through 4 present matrix diagrams, created by MiniTab Statistical 
Software, for all courses. Note the matrix diagrams are presented exactly as produced by the MiniTab Statistical Software: the upper right and lower left quadrants show the inverse relationships between factors and are, in this sense, redundant. These matrix diagrams give all possible scatter plots between each pair of the four factors, e.g., homework and average quiz score (Quiz), average test score (Test) and final examination (Final), and so forth. The scatter diagrams for average homework grades are shown in the first column and first row of the matrix plot. Whereas approximately linear relationships are evident among the quiz, test and final exam grades, the relatively weak correlation between homework and the other measures is apparent. Note that no quizzes are given in Engineering Administration (EMGT 170).

\section{ENGR 20}

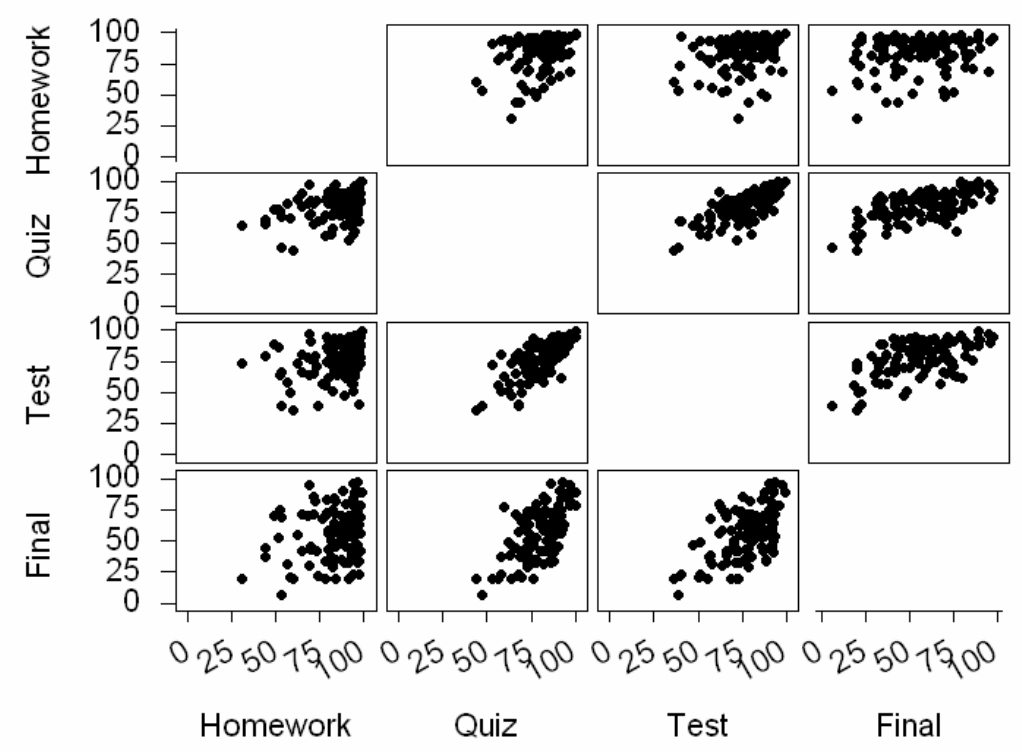

Figure 1. Matrix Plot for ENGR 20 (Statics) 
CIVL 130

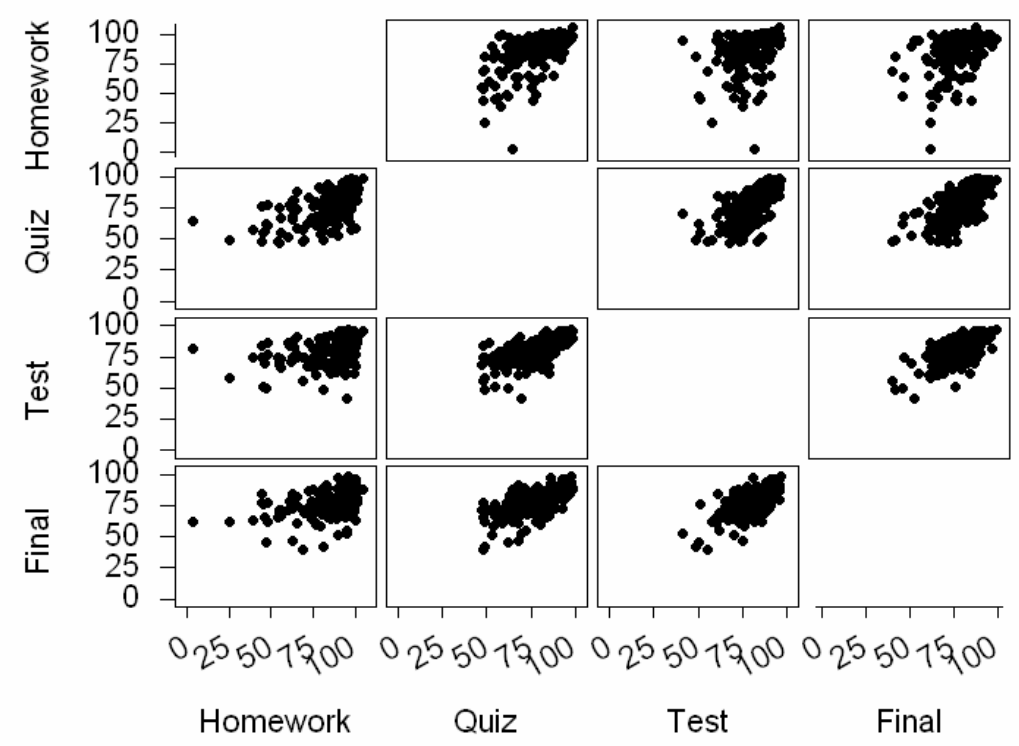

Figure 2. Matrix Plot for CIVL 130 (Fluid Mechanics)

CIVL 133

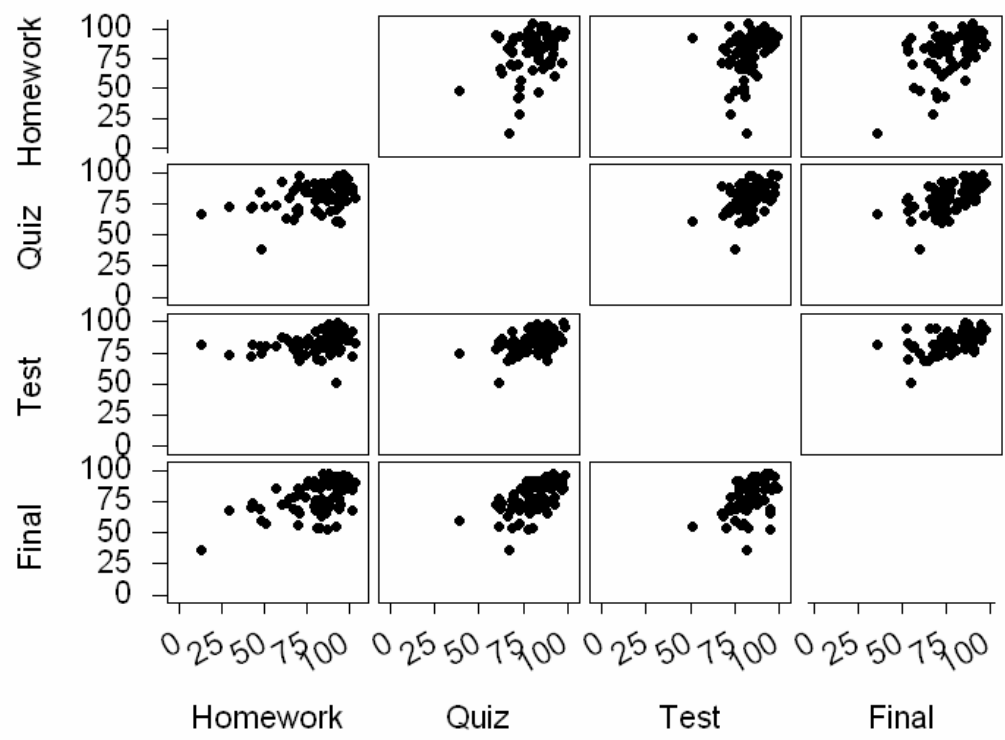

Figure 3. Matrix Plot for CIVL 133 (Water Resources Engineering) 


\section{EMGT 170}

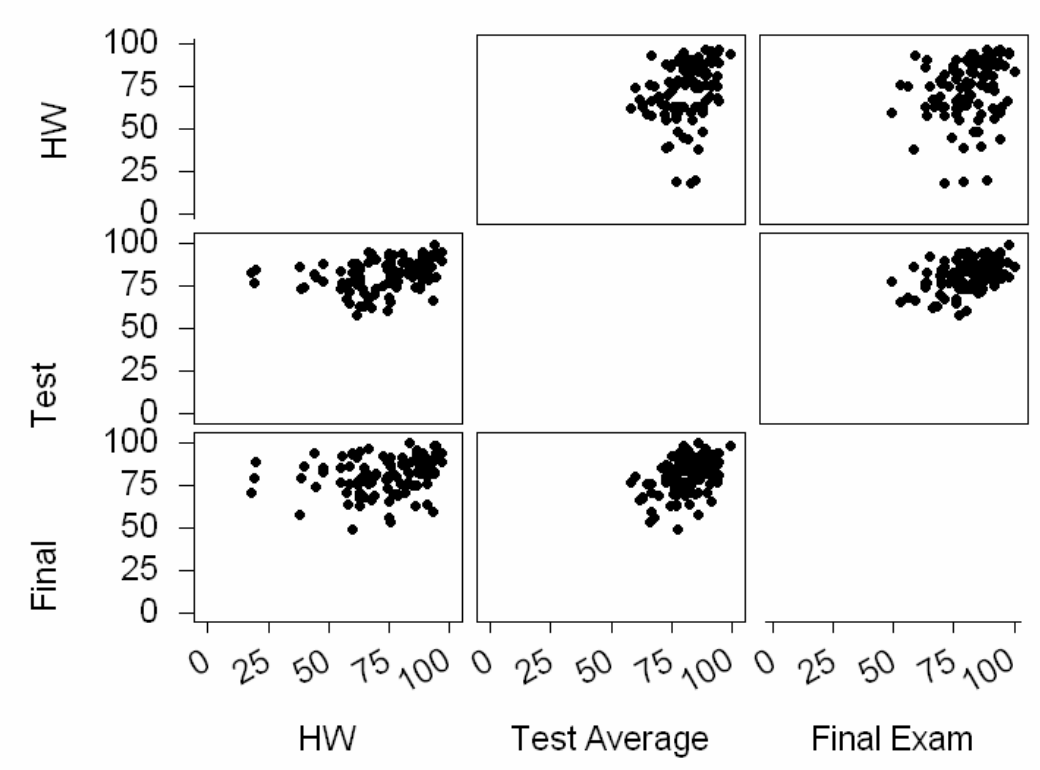

Figure 4. Matrix Plot for EMGT 170 (Engineering Administration)

Statistical analysis software was used to calculate the Pearson correlation coefficients between variables for all four courses. Results of this analysis, shown in Table 2, corroborate the visual observations shown in the matrix plots: test grades (i.e., quiz, test and final examination) are more closely correlated than homework to any of the test grades. It should be noted that quizzes were not administered in EMGT 170 and its final examination was not cumulative, thus the NA entries in Table 2.

Although there are no universally accepted criteria for defining strong, moderate or weak associations between variables, as a rule of thumb correlation coefficient values of less than 0.30 indicate little if any relationship between the variables ${ }^{9}$. Another, more classical, interpretation of correlation coefficient, $R$, is that values in the range $[0,0.20]$ indicate no correlation between variables, values in the range $[0.20,0.40]$ indicate a low degree of correlation, values of $[0.40,0.60]$ indicate a moderate degree of correlation, and values of $[0.60,0.80]$ indicate a marked, substantial degree of correlation ${ }^{10}$. On this basis, all correlations between quiz, tests and final examination scores exhibit a moderate to marked correlation between variables, with associated significance probability of $\mathrm{p}<$ 0.001. The correlations involving homework scores, in contrast, generally indicate lower degrees of relationships between variables, at lower significance levels. The $p$ value tests the null hypothesis that the correlation between the two variables is 0 , and that the calculated $\mathrm{R}$ is merely the result of random chance. For example, the correlation between Test and Final scores for ENGR 20 has an associated $\mathrm{p}<0.001$ signifying that if the true value of $\mathrm{R}$ is 0 then there is less than $0.1 \%$ likelihood of obtaining an $\mathrm{R}=0.555$. Results with values of $\mathrm{p} \leq 0.01$ are generally considered to be statistically significant (although this is dependent on the application context). 


\begin{tabular}{|l|c|c|c|c|c|}
\cline { 2 - 6 } \multicolumn{1}{c|}{} & ENGR 20 & CIVL 130 & CIVL 133 & $\begin{array}{c}\text { EMGT } \\
\mathbf{1 7 0}\end{array}$ & Average \\
\hline Homework and Quiz & $0.316^{* *}$ & $0.566^{*}$ & $0.339^{* *}$ & NA & 0.407 \\
\hline Homework and Test & $0.272^{* *}$ & $0.343^{*}$ & $0.317^{* *}$ & $0.302^{* *}$ & 0.309 \\
\hline Homework and Final & $0.228^{* *}$ & $0.423^{*}$ & $0.520^{*}$ & 0.236 & 0.352 \\
\hline Quiz and Test & $0.716^{*}$ & $0.661^{*}$ & $0.459^{*}$ & NA & 0.612 \\
\hline Quiz and Final & $0.601 *$ & $0.674^{*}$ & $0.567^{*}$ & NA & 0.614 \\
\hline Test and Final & $0.555^{*}$ & $0.673^{*}$ & $0.496^{*}$ & $0.434 *$ & 0.575 \\
\hline$* \mathrm{p}<0.001 ; * * \mathrm{p}<0.01$ & & & & \\
\hline
\end{tabular}

Table 2. Pearson Correlation Coefficients All Data Values

In a previous study of three undergraduate mechanical engineering courses, Green ${ }^{3}$ reports correlation coefficients between quiz average and final examination in the range of $[0.51,0.73]$. Thus, results of the present study are consistent with those presented by Green.

The matrix plots showed that although the preponderance of students had very high homework grades, there is a sub-population that scored very poorly. Although each instance was not examined for individual situational understanding, the collective judgments of the faculty was that this subset of students make a trade-off analysis and consciously choose not to complete homework (or complete it very poorly). Since the hypothesis posited is that graded homework may not be a significant factor in the determination of student performance on tests, only those students making a bona fide attempt to complete homework should be considered. The course instructors all had liberal partial credit grading policies, such that 50 and 60 percent cutoffs could be nominally defined as indicative of students not devoting serious effort to the homework assignments.

Two additional sets of Pearson correlation coefficients were calculated for filtered data sets that excluded students with an average homework score of less than 50 and 60 percent, respectively. The size of the original data set and the percentage of students excluded in the filtered data sets are shown in Table 3. Note the consistency across all four courses: approximately $5 \%$ of students had average homework scores below 50 percent, and $10 \%$ had a grade below 60 percent. 


\begin{tabular}{|l|c|c|c|c|c|}
\cline { 2 - 6 } \multicolumn{1}{c|}{} & ENGR 20 & CIVL 130 & CIVL 133 & EMGT 170 & Average \\
\hline $\begin{array}{l}\text { Number of students in } \\
\text { original data set }\end{array}$ & 108 & 185 & 74 & 168 & 134 \\
\hline $\begin{array}{l}\text { Percentage of students with } \\
\text { homework average < 50 }\end{array}$ & $3.7 \%$ & $5.4 \%$ & $8.1 \%$ & $6.0 \%$ & $5.8 \%$ \\
\hline $\begin{array}{l}\text { Percentage of students with } \\
\text { homework average < 60 }\end{array}$ & $9.3 \%$ & $8.1 \%$ & $10.8 \%$ & $10.7 \%$ & $9.7 \%$ \\
\hline
\end{tabular}

\section{Table 3. Original Data Set and Percentage of Students Filtered}

Results of this analysis, presented in Figures 5 and 6, show that the previously noted relationships between variables are accentuated in the filtered data sets. Correlation coefficients between homework and quiz, test or final examination are distinctly lower than those between quiz, test and final examination, respectively. Thus, for the 90 to 95 percent of students assumed to complete homework, homework exhibits no or a low degree of correlation with quiz, test or final examination scores.

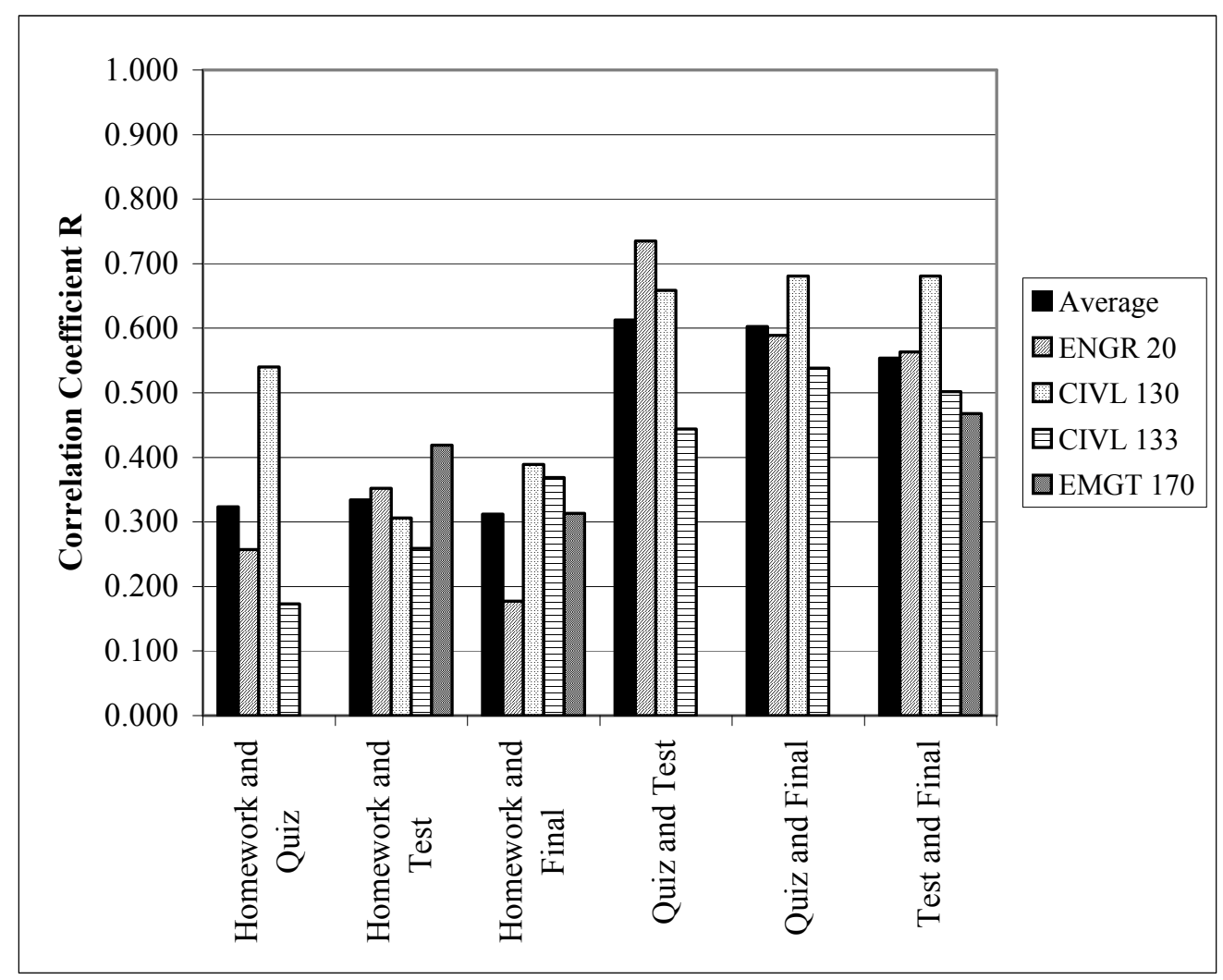

Figure 5. Pearson Correlation Coefficients Filtered Data (Homework >50\%) 


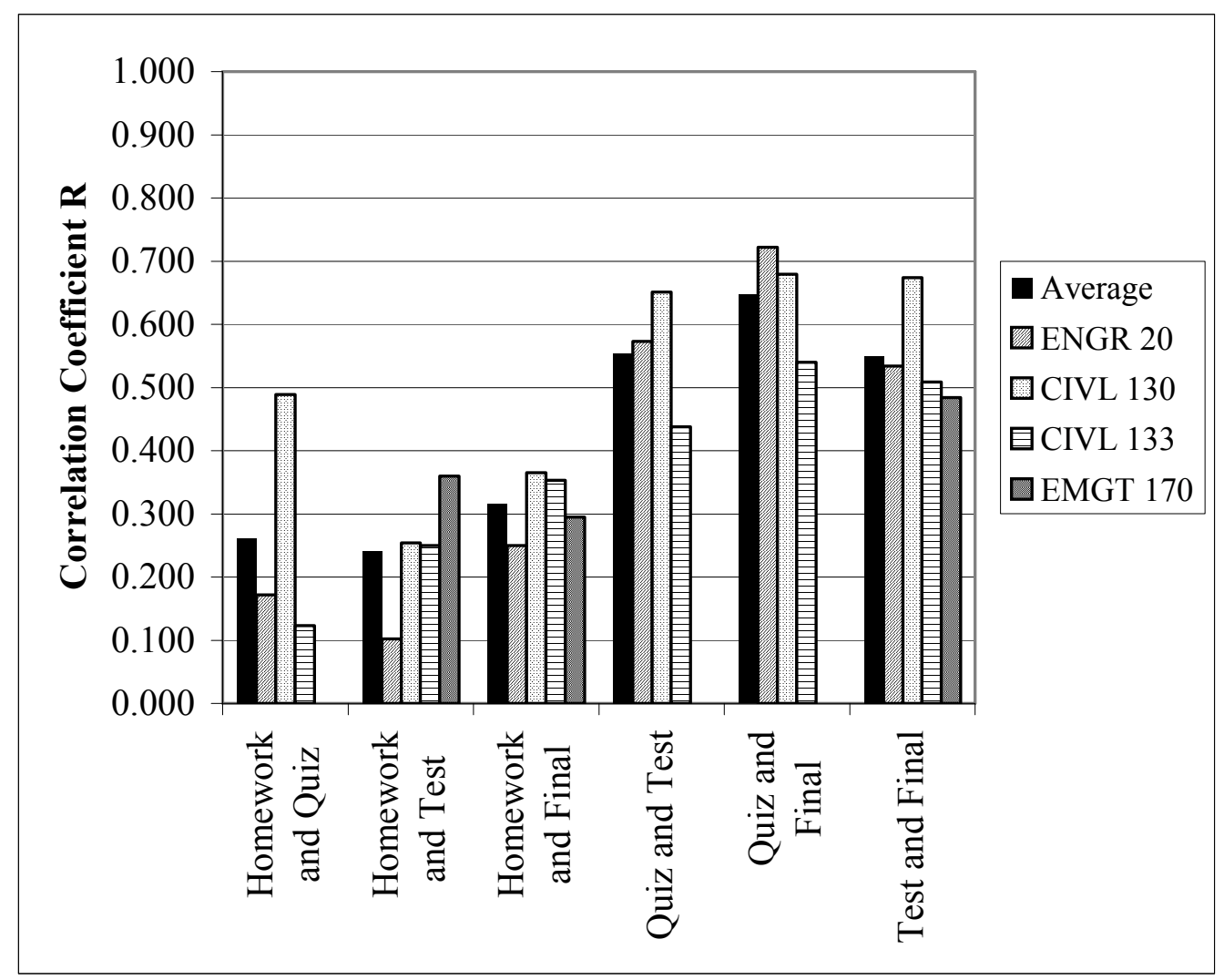

Figure 6. Pearson Correlation Coefficients Filtered Data (Homework >60\%)

Another interpretation arising from the Pearson correlation coefficient is calculation of $\mathrm{R}^{2}$, the coefficient of determination. The value of $\mathrm{R}^{2}$ indicates the percentage of variation in one variable that can be explained by the variation in the other. Table 6 gives the $\mathrm{R}^{2}$ values for combinations of variables in all courses (corresponding to the Pearson correlation coefficients, $\mathrm{R}$ values, given in Table 2). Recall that these data sets include all students taking the respective course. In all courses, the $\mathrm{R}^{2}$ value associated with homework is markedly lower than the others. With the exception of some values in CIVL 130 and 133, the variation in homework scores explains little if any of the variation in quiz, test or final examination scores, respectively.

\begin{tabular}{|l|l|l|l|l|}
\hline ENGR 20 & CIVL 130 & CIVL 133 & EMGT 170 & Average \\
\hline
\end{tabular}

\begin{tabular}{|c|c|c|c|c|c|}
\hline Homework and Quiz & 0.100 & 0.320 & 0.115 & NA & 0.178 \\
\hline Homework and Test & 0.074 & 0.118 & 0.100 & 0.091 & 0.096 \\
\hline Homework and Final & 0.052 & 0.179 & 0.270 & 0.056 & 0.139 \\
\hline Quiz and Test & 0.513 & 0.437 & 0.211 & NA & 0.387 \\
\hline Quiz and Final & 0.361 & 0.454 & 0.321 & NA & 0.379 \\
\hline Test and Final & 0.308 & 0.453 & 0.246 & 0.188 & 0.299 \\
\hline
\end{tabular}

Table 6. $R^{2}$ Values for All Data Values 
To examine only those students evidently making a serious effort to complete the homework, the data were filtered to only include students with homework average scores greater than $50 \%$ and $60 \%$, respectively. Figures 7 and 8 give the $\mathrm{R}^{2}$ values for these two filtered data sets (corresponding to the $\mathrm{R}$ values given in Figures 5 and 6 , respectively). Once these possibly anomalous data are removed, homework accounts for little of the variation in quiz, test or final examination scores (with the notable exception of quiz scores in CIVL 130).

Several factors may contribute to variations shown in Figure 8. Problems on quizzes in both ENGR 20 and CIVL 130 are similar in type, length, and format to problems solved for homework. In fact, some problems are either the same as or similar to problems provided in the textbooks. However, by the time they take CIVL 130 during their $3^{\text {rd }}$ or $4^{\text {th }}$ year, students may have developed more effective study skills and may be more conscientious about understanding the material covered in homework. Even though many students work as part of a group to complete homework assignments in CIVL 130, there seem to be fewer incidents of copying or heavy reliance on more knowledgeable peers than in ENGR 20. Data on study skills will be necessary to further support this observation. Quizzes in CIVL 133 are not necessarily similar to homework problems, as most homework assignments involve designing one or more components of a system and therefore are longer than would be appropriate for inclusion on a quiz. Problems used on tests in CIVL 130, 133, and EMGT 170 include problems similar to homework problems and those that require synthesis of knowledge. Completion of homework assignments to gain mastery of the topic should improve students' performance on exams, and this behavior may be more common among students at the upper division level. 


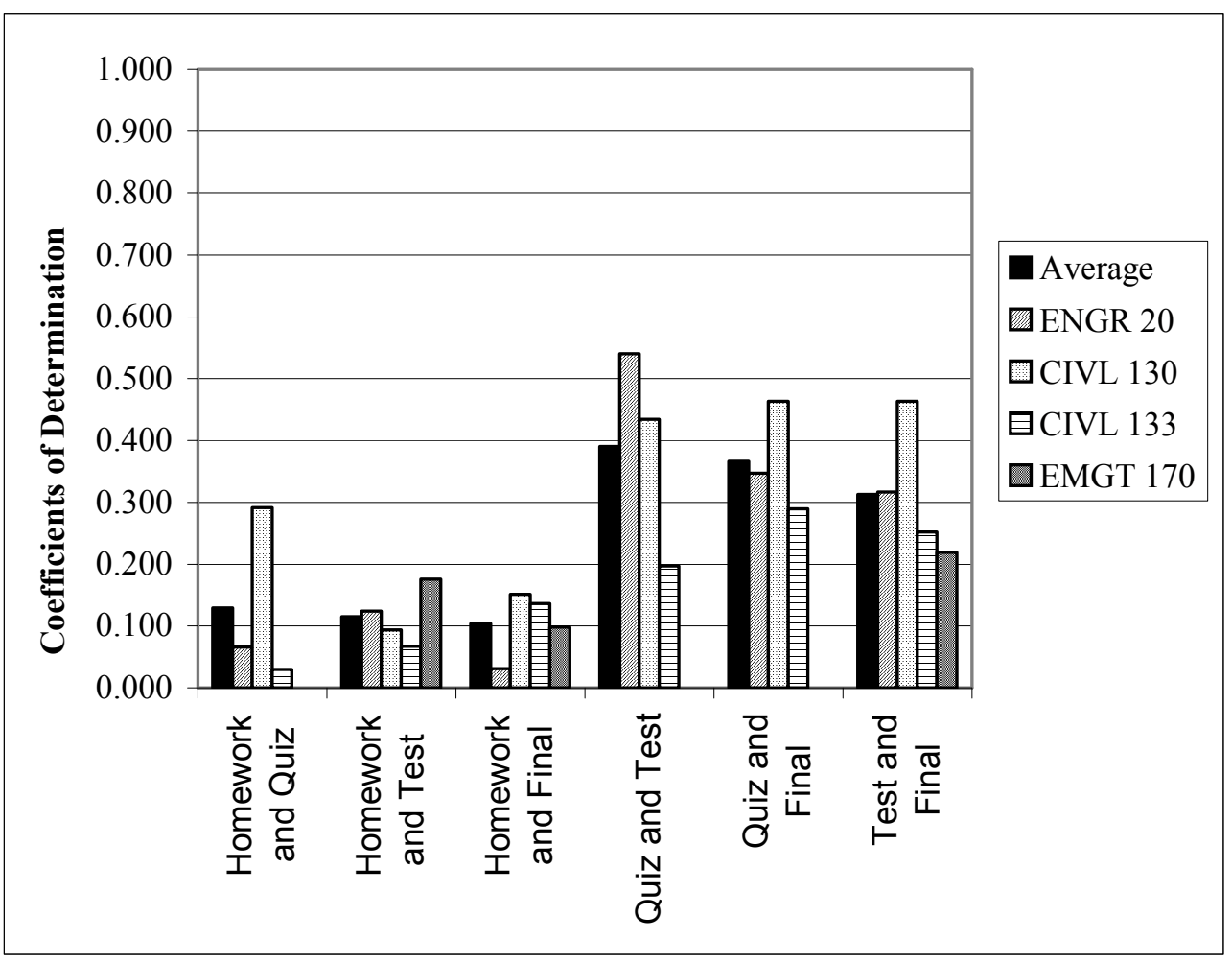

Figure 7. Coefficients of Determination $R^{2}$ Filtered Data (Homework $>50 \%$ )

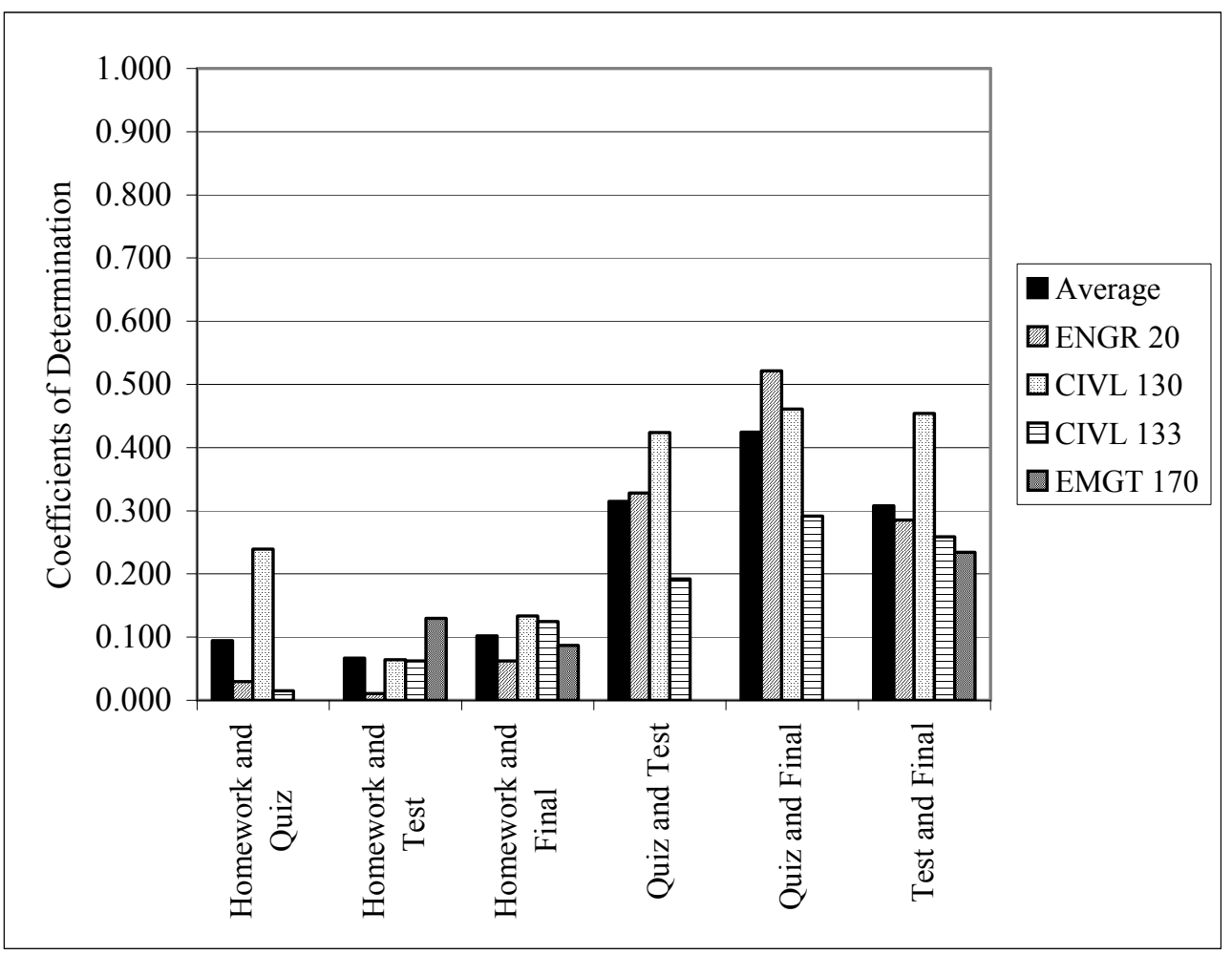

Figure 8. Coefficients of Determination $R^{2}$ Filtered Data (Homework $>60 \%$ ) 
Since a well designed cumulative final examination ideally reflects mastery of the key topics in a course, multiple linear regressions were developed for ENGR 20, CIVL 130 and CIVL 133 (recall the final exam in EMGT 170 is not cumulative) to predict a student's final examination score based on their average homework, quiz and test scores. The multiple linear regression coefficients for CIVL 130, shown in Table 9, are representative of results. The $\mathrm{R}^{2}$ for this regression is 0.551 , but as indicated by the $\mathrm{T}$ values, only the constant, Quiz and Test coefficients are statistically significant. The $T$ value (with corresponding probability, $\mathrm{p}$ ) tests the null hypothesis that the true value of a coefficient is 0 . Thus, the $p=0.001$ associated with the constant signifies that if the true value of the constant is 0 then there is a probability of $0.1 \%$ of getting a value of 15.823 for the constant.

\begin{tabular}{|l|c|c|c|c|}
\hline Predictor & Coefficient & Std. Deviation & T & p \\
\hline Constant & 15.823 & 4.486 & 3.53 & 0.001 \\
\hline Homework & 0.054 & 0.041 & 1.32 & 0.188 \\
\hline Quiz & 0.300 & 0.063 & 4.75 & 0 \\
\hline Test & 0.427 & 0.069 & 6.15 & 0 \\
\hline
\end{tabular}

Table 9. CIVL 130 Multiple Regression Results Including Homework

A second multiple linear regression was developed, this time only using average quiz and test scores as predictor variables for final examination score. The resulting multiple linear regression has an $\mathrm{R}^{2}$ of 0.547 and, as shown in Table 10, the constant, Quiz and Test coefficients are statistically significant.

\begin{tabular}{|l|c|c|c|c|}
\hline Predictor & Coefficient & Std. Deviation & T & p \\
\hline Constant & 17.695 & 4.266 & 4.15 & 0 \\
\hline Quiz & 0.340 & 0.055 & 6.13 & 0 \\
\hline Test & 0.423 & 0.069 & 6.08 & 0 \\
\hline
\end{tabular}

Table 10. CIVL 130 Multiple Regression Results Excluding Homework

Resulting multiple regression results for ENGR 20 and CIVL 133 exhibit similar characteristics. In both cases, multiple linear regressions for predicting final examination scores have $\mathrm{R}^{2}$ values in the range of $[0.39,0.43]$ with only the constant, quiz and test coefficients statistically significant.

\section{Conclusions and Future Research}

Although this study is a preliminary look at the hypothesis that graded homework is not a significant factor in determining a student's performance on tests, the results indicate there is little correlation between individual student performance on homework and performance on quizzes, tests and final examinations, respectively. Although there was greater correlation between performance on homework and quizzes in the data analyzed for CIVL 130 than for the other courses included in this study, the degree of correlation could only be characterized as "moderate". These results, in conjunction with those of Trussel and $\mathrm{Dietz}^{8}$, indicate the need for additional research regarding the effectiveness 
of imposing mandatory graded homework. If test scores are the de facto principal criterion for assessing student learning in a course, then results of this study indicate that the resources committed to graded homework may well be reallocated to other means of enhancing student learning ${ }^{3}$. It could even be argued that homework grades perhaps overstate a student's true conceptual understanding of the subject matter and perhaps tend to distort final grades. In some cases this distortion may be downward: some students appear to not expend the required level of effort on homework (perhaps in a conscious allocation of their time) and yet still perform relatively well on tests. Others get high grades on homework, perhaps by relying on help from peers, yet perform poorly on tests.

Although these findings indicate that high homework scores do not seem to lead to high test scores, the authors believe that effective homework assignments do provide benefits important to engineering education. Homework assignments develop practical and personal insights into the application of engineering concepts difficult to appreciate by merely reading a textbook. Students develop problem solving skills through repeated application of the problem solving process, perhaps a distinguishing characteristic of the engineering discipline. In addition, strict homework submittal policies, and enforcement through grading, emphasize the importance of professionalism in the engineering discipline. These benefits may be available through an optional homework submittal policy; however, the consensus among students and faculty seems to be that required submittal and grading of homework is a strong motivator for a large proportion of students. Thus, these collateral benefits are likely to accrue only if homework is graded.

This study was motivated by a desire to improve student learning outcomes and recognition of the need to effectively use limited resources. The underlying pedagogical objective is to develop a well designed homework strategy within engineering courses. This strategy encompasses the percentage weight assigned to homework (sufficient to act as a motivator but not distort a true assessment of student proficiency in the subject matter), the frequency and types of problems assigned as homework, the use of on-line resources to supplement or supplant traditional homework, and other aspects of homework within engineering courses ${ }^{11}$. It is likely student behavioral subpopulations exist: some engineering students may be helped by graded homework while others may exploit "study groups" and do not benefit from imposed homework (benefit as measured by test performance). If such subpopulations do exist, then an open question is how to motivate each student to perform while optimizing student learning and allocation of instructor time and resources.

A number of research areas are natural extensions to the present study. Perhaps the most pressing is to examine the research hypothesis using a well structured experimental design. The data in our present analysis was collected on an after the fact basis, and did not result from a experiment conducted using traditional research methodology. The conclusions derived from analysis of the data should, therefore, be considered in light of the study limitations. Future experimental design should take into account such factors as: 
- homework grading rubrics across courses,

- mapping of homework to test questions,

- feedback provided as part of homework grade, and

- degree and effectiveness of group work in homework.

In addition to the above, other research areas are also potential extensions of the present study. One such area for future exploration is the replacement of mandatory graded homework with more frequent in-class quizzes. If test instruments are the de facto principal means of assessing student knowledge outcomes, then frequent quizzes could perhaps be a more effective and efficient means of motivating student learning. Homework could be assigned but not graded, with classroom discussion and web solution posting providing feedback to student work. The authors are planning to test this hypothesis in a future Statics course. Another research direction is investigating the actual proportion of individual work in homework assignments. Although students are encouraged to seek help as necessary to understand assignments, all homework submittals are expected to reflect individual work. The results of this study seemingly contradict this guideline. Are students, to the ultimate detriment of their test performance, not following this honor code guideline? The authors are currently conducting a controlled experiment to further understand the role, extent and impact of student reliance upon others for homework. If a significant proportion of students rely on the assistance of others for homework, then motivating each student to perform while optimizing student learning and allocation of instructor time and resources is yet another open research question. The overall research direction is the investigation of the effectiveness of existing pedagogy (i.e., mandatory homework policy) and the development of more effective and efficient approaches.

\section{Bibliography}

1. Cerrito, P.B., and Levi, I., "An Investigation of Student Habits in Mathematics Courses," College Student Journal, Vol. 33, No. 4, 1999, pp. 584-589.

2. "Criteria for Accrediting Engineering Programs", ABET Engineering Accreditation Commission, November 2004.

3. Green, S., "Student Assessment Precision in Mechanical Engineering Courses," Journal of Engineering Education, Vol. 94, No. 2, 2005, pp. 273-278.

4. Cooper, H., "Synthesis of Research on Homework," Educational Leadership, Vol. 43, NO. 3, 1989, pp. 141-146.

5. Gill, B.P., and Schlossman, S.L., "Villain or Savior? The American Discourse on Homework, 18502003," Theory Into Practice, Vol. 43, No. 3, 2004, pp. 174-182.

6. Walberg, H.J., and Paschal, R.A., "Howework's Powerful Effects on Learning”, Educational Leadership, Vol. 42, No. 7, 1985, pp. 76-79. 
7. Aldosary, A.D., "The Correlation between Final Grade Score, Attendance and Homework in the Performance of CED Students," European Journal of Engineering Education, Vol. 20, No. 4, 1995, pp. 481-486.

8. Trussell, H.J., and Dietz, E.J., "A Study of the Effect of Graded Homework in a Preparatory Math Course for Electrical Engineers," Journal of Engineering Education, Vol. 92, No. 2, 2003, pp. 141-146.

9. Hinkle, D., Wiersma, W., and Jurs S., Applied Statistics for the Behavioral Sciences, $5^{\text {th }}$ Edition, Houghton Miffin Co., 1998.

10. Franzlau, A., A Primer of Statistics for Non-Statisticians, Harcourt, Brace \& World, 1958.

11. Cheng, K.K., Thanker, B.A., Cardenas, R.L., and Crouch, C., "Using an On-line Homework System Enhances Students' Learning of Physics Concepts in an Introductory Physics Course," American Journal of Physics, Vol, 72, No. 11, 2004, pp. 1447-1454. 